\title{
EMPIRICAL RESEARCH ON THE EFFECTIVENESS OF MOMENTUM STRATEGIES IN SHANGHAI STOCK MARKET
}

\author{
Zhenyu Zhao \\ Shanghai University, P.R.China \\ Xiemin Liao \\ Shanghai University, P.R.China
}

\begin{abstract}
The effectiveness of momentum strategies and contrarian strategies is an important component to reflect market characteristics. This paper employs the market adjustment model, which segmentally examines the effectiveness of the momentum strategies of the Shanghai stock market from July 2014 to April 2016. The empirical results show that the contrarian strategies are remarkably effective in the full cycle. The momentum strategies are effective in short term of bull cycle, while contrarian strategies are more applicable to bear market.
\end{abstract}

Keywords: momentum strategies; contrarian strategies; market adjustment model

\section{JEL code: G11-Portfolio Choice}

\section{Introduction}

Momentum effect means that the portfolio will continue the performance of early stage in the future, which reflects the underreaction of market. In contrast to momentum effect, contrarian effect means that the future performance of the portfolio is contrary to its performance of early stage, which reflects the overreaction of market. As a result, momentum strategies call for buying portfolios that have been performing well over the past period of time, while selling portfolios performed poorly. Contrarian strategies call for buying portfolios that have been performing poorly over the past period of time, while selling portfolios perform well.

Since 1980s, the studies of overreaction and underreaction have been fruitful. Debondt and Thaler $(1985,1987)$ sorted stocks performed best and stocks performed poorliest of the New York stock market over the past three years, obtaining "winner" portfolio formed by 35 stocks performed best and "loser" portfolio formed by 35 stocks performed poorliest. By examining 
the market performance of these two portfolios in the next three years, they found that the yield of "loser" portfolios was significantly higher than that of "winner" portfolios, and there was the contrarian effect in the market.

Jegadeesh and Titman (1993) found that the portfolio, buying 10\% of the stocks with the highest yield in the past 3-12 months and selling $10 \%$ of the stocks with the lowest yield of the same period, can obtain better returns in the next 3-12 months, which reflected that there was the momentum effect in American stock market, and momentum strategies were put forward accordingly.

Rouwenhorst (1998) used the method of Jegadeesh and Titman (1993), taking stock data of 12 European countries as samples. The study results showed that momentum effect existed in European stock market.

Chui (2010) and others studied the momentum strategies of stock market in 72 countries. The results showed that there was insignificant momentum effect in Chinese stock market in momentum strategies whose forming periods and holding periods both are 6 months.

Chen Ke and Chen Wei (2017) back-tested the historical data of Shanghai Composite Index. Momentum strategies is effective for long equities and short equities. Trading results can obtain significant abnormal returns. The daily returns of momentum strategies can get $0.04 \%-0.08 \%$ daily abnormal return beyond the daily returns of Shanghai Composite Index.

Yang Bin, etc. (2015) divided the bear market and bull market into four cycles by using all the transaction data of A Share in Shanghai Stock Exchange and A Share in Shanghai Stock Exchange during 1990 to 2014. The results showed that momentum strategies produced significantly abnormal returns in the short term, but it was not significant for periods over six months. It was also found that the existence and the existence form of the abnormal returns of momentum strategies are highly correlated with the market stage; there is a significant momentum effect in the bull cycle, and the more in the bear cycle is the contrarian effect.

Huang Weihua (2015) studied the data of the Shanghai and Shenzhen stock markets from January 1995 to December 2012. The results showed that when the sorting periods and holding periods were one month or three months, the "winner" portfolios had a contrarian effect; when the sorting periods and holding periods were nine months or twelve months, the "winner" portfolios had a momentum effect. 
Wang Yi (2007) studied Chinese stock data from 1994 to 2006, and analyzed stocks by market value. The results of the study showed that in the Chinese stock market, the momentum strategies are suitable for the stocks of a large company, while contrarian strategies are suitable for the stocks of a small company.

In addition, Zhou Linjie (2002), Zhu Zhanyu (2003), Yan Taihua and Liang Lan (2011) have been able to conclude that the short-term momentum effect exists in the Chinese stock market through empirical analysis. Wang Yonghong and Zhao Xuejun (2011), Liu Bo and Pi Tianlei (2007), Liu Xiaolei (2011), Yang Deyong and Wang Jiaqing (2013) have been able to conclude that there is significant contrarian effect in Chinese stock market.

Chinese stock market is a new market, with characteristics of short history, high risk, high speculativeness, high turnover rate and so on. Using the De bondt-Thaler method, this paper divides the research period into bull cycle and bear cycle, and avoids the self-correlation of the data by non-overlapping sampling. This paper tests whether there is the momentum effect in Shanghai stock market with forming periods and holding periods in weeks.

\section{The Idea, Data and Model of Empirical Research}

\subsection{The idea of empirical research}

First of all, the study periods are divided into forming periods (F periods) and holding periods (H periods), respectively set to 2 weeks, 4 weeks, 6 weeks, and divided into 9 groups (as shown in Table 1). Calculate the cumulative abnormal return by market adjusted model, then 50 stocks perform best in forming periods form "winner" portfolios (W) and 50 stocks performed poorliest formed "loser" portfolios (L). Secondly, the paper analyzes the investment effect of three different trading strategies [buying W, selling L, buying W and selling L (W-L)] in holding periods. Finally, this paper divides the research period into bear cycle and bull cycle to compare the momentum effect and reverse effect in different market situation. 
Table 1. Forming periods, holding periods and sample periods

\begin{tabular}{|c|c|c|c|c|c|c|c|c|c|}
\hline Forming & \multicolumn{3}{|c|}{2 weeks } & \multicolumn{3}{|c|}{4 weeks } & \multicolumn{3}{|c|}{6 weeks } \\
\hline $\begin{array}{l}\text { Holding } \\
\text { Periods }\end{array}$ & $\begin{array}{c}2 \\
\text { weeks }\end{array}$ & $\begin{array}{c}4 \\
\text { weeks }\end{array}$ & $\begin{array}{c}6 \\
\text { weeks }\end{array}$ & $\begin{array}{c}2 \\
\text { weeks }\end{array}$ & $\begin{array}{c}4 \\
\text { weeks }\end{array}$ & $\begin{array}{c}6 \\
\text { weeks }\end{array}$ & $\begin{array}{c}2 \\
\text { weeks }\end{array}$ & $\begin{array}{c}4 \\
\text { weeks }\end{array}$ & $\begin{array}{c}6 \\
\text { weeks }\end{array}$ \\
\hline Periods & $45^{\circ}$ & 44 & 43 & 22 & 22 & 21 & 15 & 14 & 14 \\
\hline
\end{tabular}

\subsection{The selection of sample data}

This paper selects the weekly yield data of sample stock of Shanghai stock market, whose source is Wind database.

The paper divides the entire research period into the bull cycle and bear cycle; the bull cycle is from July 1, 2014 to June 12, 2015 and the bear cycle is from June 15, 2015 to March 31, 2016.

The selection of sample stocks excluded the stocks that were suspended or specially disposed, that is, each of the 100 stocks in forming periods selected does not include the stocks that were suspended or specially disposed.

\subsection{Construction of the Empirical Model}

This paper uses the De bont-thaler method to calculate the cumulative abnormal return.

1. Calculate the cumulative abnormal return of stocks in forming periods

$$
\begin{aligned}
& F A R_{i, t}=\frac{P_{i, t}}{P_{i, t-1}}-\frac{P_{m, t}}{P_{m, t-1}} \\
& F C A R_{i}=\sum_{t=1}^{F} A R_{i, t}
\end{aligned}
$$

Among above:

$P_{i, t}$ means the closing price of stock $i$ in the $\mathrm{t}$-th week

$P_{m, t}$ meas the closing index of Shanghai Composite Index in the t-th week 
$F A R_{i, t}$ means the abnormal return of stock $i$ in the t-th week

$F C A R_{i}$ means the cumulative abnormal return of stock $i$ in forming periods

2. Calculate the cumulative abnormal return of stocks in holding periods

Sort the cumulative abnormal return of each stock obtained in the first step, then 50 stocks with highest cumulative abnormal return form "winner" portfolios and 50 stocks with lowest cumulative abnormal return form "loser" portfolios. Separately calculate the cumulative abnormal return of "winner” portfolios and "loser” portfolios in holding periods.

$$
\begin{aligned}
& H A R_{i, t}=\frac{P_{i, t}}{P_{i, t-1}}-\frac{P_{m, t}}{P_{m, t-1}} \\
& H C A R_{i}=\sum_{t=1}^{H} A R_{i, t}
\end{aligned}
$$

Among above:

$H A R_{i, t}$ means the abnormal return of stock $i$ in the $\mathrm{t}$-th week

$H C A R_{i}$ means the cumulative abnormal return of stock $i$ in holding periods

\section{Construct the return series}

Obtain the cumulative abnormal return of 100 sample stocks (50 in “winner” portfolios and 50 in "loser" portfolios) in each corresponding forming period and holding period from the first and second step, then separately calculate the average cumulative abnormal return of "winner" portfolios and "loser" portfolios in holding periods.

$$
A H C A R=\frac{1}{50} \sum_{i=1}^{50} H C A R_{i}
$$

Among above:

AHCAR means the average cumulative abnormal return of portfolios in holding periods. 
4. Change a forming period and holding period, repeat the previous three steps until finishing all combination of forming periods and holding periods.

\section{Empirical Results}

\subsection{The average cumulative abnormal return in different periods}

This paper uses the moving window to repeat sampling in the corresponding sample period and obtains the average cumulative abnormal return in different periods, as shown in Table 2, Table 3 and Table 4.

Table 2. AHCAR of "winner" and "loser” in different holding periods, of which forming period is 2 weeks.

\begin{tabular}{|c|c|c|c|c|c|c|c|}
\hline \multicolumn{4}{|c|}{ "winner" portfolios } & \multicolumn{4}{|c|}{ "loser" portfolios } \\
\hline $\mathrm{F}=2$ & $\mathrm{H}=2$ & $\mathrm{H}=4$ & $\mathrm{H}=6$ & $\mathrm{~F}=2$ & $\mathrm{H}=2$ & $\mathrm{H}=4$ & $\mathrm{H}=6$ \\
\hline 18.9136 & -4.0171 & -0.4044 & 1.985 & -8.3427 & -3.0088 & 0.7272 & 5.1779 \\
\hline 14.6816 & -0.2095 & 1.3782 & 0.4709 & -13.0972 & 5.5183 & 10.0874 & 11.3311 \\
\hline 20.0902 & 2.0485 & 2.5118 & 4.0803 & -6.8507 & 3.1258 & 3.234 & 4.788 \\
\hline 27.306 & 1.7227 & 1.2451 & 4.7774 & -6.4419 & -0.5655 & -0.985 & -0.1517 \\
\hline 20.904 & 0.8212 & 3.5156 & 1.2552 & -8.425 & -0.0565 & 2.1718 & 1.7973 \\
\hline 23.4031 & 2.5835 & 2.4588 & 0.6111 & -6.7712 & 0.4039 & -1.2098 & -3.3989 \\
\hline 18.3646 & 1.1335 & 2.6205 & -2.3198 & -4.9808 & -0.2563 & -1.3933 & -5.9155 \\
\hline 23.5172 & 0.2609 & -5.8494 & -6.377 & -9.2758 & 1.4256 & -2.284 & -4.4291 \\
\hline 23.0308 & 0.5949 & 3.615 & 1.1868 & -3.559 & -3.2037 & -4.8857 & -12.0462 \\
\hline 21.8137 & 0.8016 & -0.0088 & -4.4457 & -14.3426 & -2.0306 & -9.8628 & -22.785 \\
\hline 29.2814 & 0.2357 & -5.9436 & -10.8346 & -10.7399 & -6.1233 & -16.4104 & -19.1237 \\
\hline 29.277 & -3.3117 & -10.1642 & -10.6513 & -20.7008 & -12.9758 & -17.3864 & -12.416 \\
\hline 24.2084 & -7.5061 & -10.9827 & -8.3025 & -24.8298 & -4.5472 & 1.1539 & 6.3167 \\
\hline 13.0488 & 3.7436 & 3.5381 & 3.2609 & -14.5729 & 1.131 & 6.2431 & 8.9641 \\
\hline 20.7215 & 3.5917 & 6.8596 & 11.4194 & -10.704 & 2.0219 & 2.151 & 4.8573 \\
\hline 35.4637 & 4.7004 & 9.3819 & 10.6973 & -7.3712 & 1.4192 & 3.3103 & 5.1058 \\
\hline 18.7307 & 3.8956 & 3.5073 & 7.2458 & -9.0819 & 4.2827 & 1.7844 & 4.7611 \\
\hline 29.486 & -0.9829 & 1.7699 & -5.1086 & -7.1818 & 1.1927 & 1.4558 & -4.0931 \\
\hline 22.2413 & 3.0926 & -1.6018 & -0.109 & -12.2144 & 2.5707 & -0.7767 & 5.3415 \\
\hline 32.753 & -6.9529 & -9.1789 & 2.1741 & -9.0721 & -7.5343 & -7.8978 & -0.9095 \\
\hline
\end{tabular}


Table 2, cont.

\begin{tabular}{|c|c|c|c|c|c|c|c|}
\hline 26.1823 & 1.7786 & 8.2651 & 16.5149 & -19.7084 & 0.8161 & 10.9995 & 18.4936 \\
\hline 34.1588 & 7.0407 & 9.9886 & 12.359 & -12.5114 & 6.1439 & 13.6437 & 16.8658 \\
\hline 51.4364 & 24.8689 & 18.0092 & 11.5227 & -11.7147 & 2.2682 & 8.5599 & 12.2222 \\
\hline 66.0266 & -5.4903 & -16.558 & -38.2035 & -14.2123 & 6.6398 & 0.7061 & -12.4173 \\
\hline 60.7672 & -1.4418 & -27.1775 & -1.9027 & -23.1604 & -9.5683 & -27.366 & -4.5276 \\
\hline 49.1058 & -18.3464 & -2.4487 & 1.4489 & -21.4493 & -20.4907 & 5.7979 & 8.7265 \\
\hline 25.105 & -10.5299 & -11.3174 & -12.9729 & -48.958 & 45.0825 & 48.3313 & 53.4163 \\
\hline 58.8835 & 2.0129 & 3.3898 & -11.6796 & -18.1344 & -2.6794 & -5.3221 & -6.1165 \\
\hline 29.0681 & -3.8673 & -15.3304 & -3.5301 & -16.4147 & 4.6873 & -13.5502 & -4.2665 \\
\hline 35.3304 & -19.6891 & -15.7503 & -12.646 & -20.2781 & -11.5014 & -1.4713 & 4.8966 \\
\hline 17.1598 & -1.9562 & -2.2889 & -3.0307 & -37.1424 & 14.9577 & 18.4667 & 27.6213 \\
\hline 37.6314 & 1.047 & 10.0849 & 12.3569 & -23.9051 & 4.9623 & 11.1517 & 13.6846 \\
\hline 22.0908 & 3.5047 & 6.9921 & 10.2426 & -15.4303 & 4.5591 & 6.5602 & 8.6757 \\
\hline 24.7966 & 2.3574 & 5.5233 & 5.7792 & -15.0444 & 1.8522 & 1.5269 & 6.7455 \\
\hline 25.2805 & 0.7141 & 5.1619 & 4.6859 & -11.2713 & 2.4435 & 3.5989 & 2.0029 \\
\hline 31.0983 & 3.8855 & 5.0778 & 7.6571 & -11.7706 & 2.4719 & 0.4522 & 2.3236 \\
\hline 37.0883 & -2.9056 & -0.2185 & -4.3391 & -12.8092 & -0.0025 & 2.1905 & -1.1932 \\
\hline 25.1995 & 3.9957 & 0.3551 & -0.7811 & -14.5608 & 1.0330 & -5.0232 & -5.9064 \\
\hline 36.1855 & 3.1267 & -1.7607 & -2.2780 & -10.9474 & -5.2676 & -7.2355 & -5.3323 \\
\hline 33.8416 & -10.9640 & -12.9544 & -11.4493 & -18.9316 & 2.2236 & 5.9128 & 7.9375 \\
\hline 20.3669 & -0.1429 & 1.1821 & -6.4717 & -21.5418 & 1.7187 & 3.5786 & -2.8203 \\
\hline 20.7249 & -0.4936 & -7.0786 & -1.9773 & -15.7459 & 2.9132 & -1.6036 & 5.0722 \\
\hline 23.0661 & -8.7267 & -5.2759 & -4.8718 & -12.5681 & -7.2432 & 3.2324 & 5.5844 \\
\hline 11.5786 & -0.3617 & 0.1335 & & -19.2059 & 8.1643 & 10.0566 & \\
\hline 26.4690 & -0.4258 & & & -8.2207 & -0.0438 & & \\
\hline
\end{tabular}


Table 3. AHCAR of "winner" and "loser" in different holding periods, of which forming period is 4 weeks.

\begin{tabular}{cccc|cccc}
\hline \multicolumn{5}{c}{ “winner” portfolios } & & \multicolumn{5}{c}{ "loser” portfolios } \\
\hline $\mathrm{F}=4$ & $\mathrm{H}=2$ & $\mathrm{H}=4$ & $\mathrm{H}=6$ & $\mathrm{~F}=4$ & $\mathrm{H}=2$ & $\mathrm{H}=4$ & $\mathrm{H}=6$ \\
\hline 21.6769 & 1.6368 & 2.9719 & 3.0721 & -15.4594 & 5.0037 & 11.5734 & 11.0634 \\
34.4567 & 2.8635 & 2.9528 & 7.2973 & -8.3339 & 0.1717 & -0.1433 & -0.7574 \\
30.4777 & 2.5725 & 0.2051 & -0.1157 & -11.4192 & 1.0418 & -0.88 & -2.5801 \\
28.168 & 1.0661 & -5.289 & -5.7886 & -9.2509 & 0.2981 & -3.3846 & -5.8505 \\
30.7958 & 3.5249 & 2.4509 & -1.4935 & -19.0102 & -0.8323 & -8.1497 & -19.8809 \\
42.1731 & -4.3436 & -10.662 & -9.4496 & -25.1247 & -14.6244 & -18.0735 & -13.4831 \\
22.4604 & -0.6611 & -0.1791 & -0.4232 & -31.1492 & 5.1995 & 10.5704 & 12.042 \\
36.2869 & 4.4032 & 7.8106 & 9.12 & -12.6815 & 1.0161 & 3.6786 & 6.4914 \\
32.6977 & 0.6139 & 4.1595 & -4.1524 & -9.1155 & 1.842 & 3.4639 & 1.6141 \\
34.3433 & -6.4101 & -7.3489 & 4.5784 & -18.0605 & -7.1294 & -0.8402 & 10.7415 \\
42.8505 & 6.0428 & 7.5874 & 9.6787 & -22.7022 & 12.6174 & 21.902 & 26.2743 \\
94.2797 & -12.0723 & -20.1395 & -40.6852 & -16.3343 & 2.3661 & 5.1767 & 2.3356 \\
70.6016 & -19.9772 & -2.3122 & 2.0173 & -36.9558 & -17.6048 & 8.9304 & 12.3865 \\
29.6271 & 0.2389 & 0.4264 & -7.7509 & -29.1243 & 1.5396 & 7.7646 & -8.0027 \\
42.2483 & -17.6527 & -9.8931 & -7.116 & -19.7293 & -14.9477 & -6.2711 & -0.6738 \\
27.656 & 0.1165 & 4.2718 & 3.4205 & -36.1569 & 10.5274 & 18.5119 & 20.7771 \\
34.8859 & 2.905 & 7.5522 & 11.0564 & -21.0542 & 5.2276 & 5.8253 & 11.5039 \\
39.9359 & 4.5008 & 4.7234 & 6.9333 & -14.6841 & 1.5824 & -0.6579 & 0.3831 \\
43.2735 & 3.2176 & -13.9742 & -23.4638 & -17.6801 & 1.0953 & -15.1869 & -24.8661 \\
36.1211 & -18.1649 & -24.8743 & -24.7700 & -35.9038 & -8.5180 & -10.8021 & -8.8049 \\
16.3200 & -0.6328 & -6.6143 & 4.8995 & -38.5666 & 2.0679 & -1.9798 & 11.0616 \\
-21.8685 & 16.1295 & 19.6724 & & -21.8685 & 16.1295 & 19.6724 & \\
\hline & & & & & & & \\
\hline
\end{tabular}


Table 4. AHCAR of "winner" and "loser" in different holding periods, of which forming period is 6 weeks.

\begin{tabular}{|c|c|c|c|c|c|c|c|}
\hline \multicolumn{4}{|c|}{ “winner” portfolios } & \multicolumn{4}{|c|}{ "loser" portfolios } \\
\hline $\mathrm{F}=6$ & $\mathrm{H}=2$ & $\mathrm{H}=4$ & $\mathrm{H}=6$ & $F=6$ & $\mathrm{H}=2$ & $\mathrm{H}=4$ & $\mathrm{H}=6$ \\
\hline 30.2701 & 1.1729 & 1.3784 & 3.4078 & -12.816 & 4.2588 & 3.6361 & 6.5682 \\
\hline 40.92 & 2.3981 & -0.5515 & -2.1251 & -11.7923 & 1.204 & 0.2523 & -1.5644 \\
\hline 35.7586 & -5.9648 & -4.6134 & -9.5348 & -12.4463 & -2.1865 & -5.0759 & -12.0641 \\
\hline 43.3253 & -1.4786 & -6.7068 & -6.1653 & -32.275 & -13.89 & -17.1741 & -13.4021 \\
\hline 26.639 & 3.7002 & 3.5787 & 6.6497 & -28.9386 & 6.5049 & 7.8333 & 12.7308 \\
\hline 54.7483 & 0.9891 & 5.5948 & -1.3876 & -9.0908 & 0.7314 & 0.852 & -0.7022 \\
\hline 39.9881 & -1.0372 & 6.1455 & 6.6301 & -28.9311 & 4.0073 & 14.5789 & 28.7401 \\
\hline 82.3333 & -5.785 & -12.2342 & -34.5533 & -18.9869 & 2.5633 & 2.4134 & 3.1271 \\
\hline 63.0882 & 7.5311 & 12.1131 & 12.0058 & -64.7592 & 38.2647 & 41.7917 & 40.6948 \\
\hline 76.8872 & -16.231 & -9.0759 & -4.3425 & -29.1997 & -6.369 & -2.09 & 1.1566 \\
\hline 31.0746 & 5.1309 & 5.0438 & 6.0057 & -32.5601 & 7.3253 & 11.2898 & 15.1542 \\
\hline 49.8153 & 2.5659 & 1.6160 & 4.8872 & -22.8105 & 7.3669 & 7.9751 & 12.5854 \\
\hline 52.4583 & -16.4439 & -26.3305 & -31.7766 & -20.4788 & -15.6628 & -25.2833 & -31.6187 \\
\hline 10.7651 & -1.5096 & -7.6686 & 3.6689 & -51.6557 & 2.8674 & -0.7254 & 13.0794 \\
\hline 33.9805 & -0.7140 & & & -8.3475 & 3.1752 & & \\
\hline
\end{tabular}

\subsection{The analysis of the full cycle}

This paper makes simple arithmetic mean on the values of AHCAR in above tables to easily compare the overall direction of the three trading strategies and at the same time, tests the significance that the average cumulative abnormal return in each holding period corresponding to each forming period is positive or negative, as shown in Figure 1 and Table 5. 
Table 5. the average values of AHCAR of momentum strategies in the full cycle

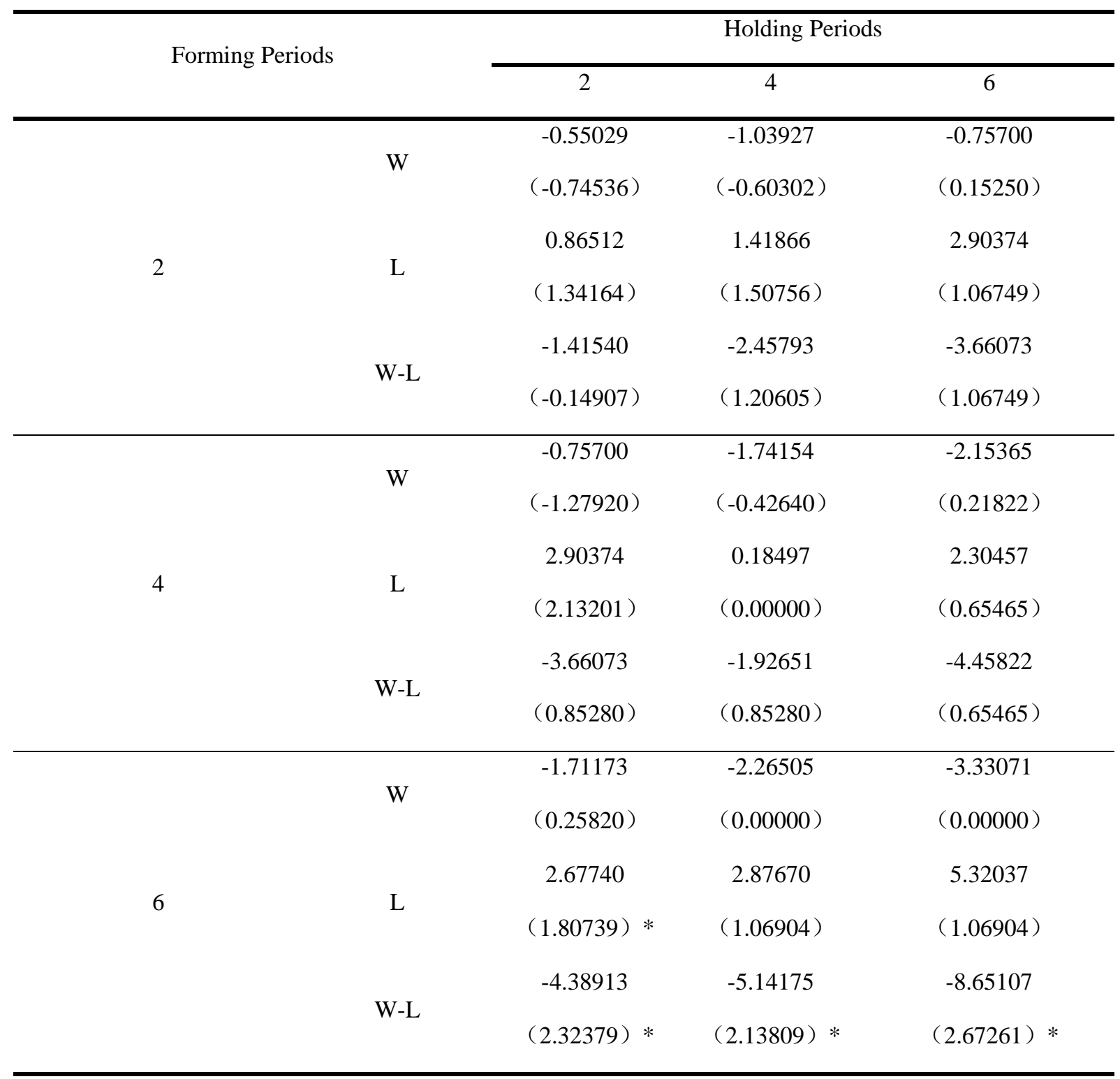

Note: The above results are the the average values of AHCAR in corresponding forming periods and holding periods. W means "winner” portfolios; L means "loser” portfolios; W-L means buying "winner” portfolios and selling "loser" portfolios. The value in parentheses is $\mathrm{Z}$, and "*" indicates that it is significant at a significant level of $10 \%$. 


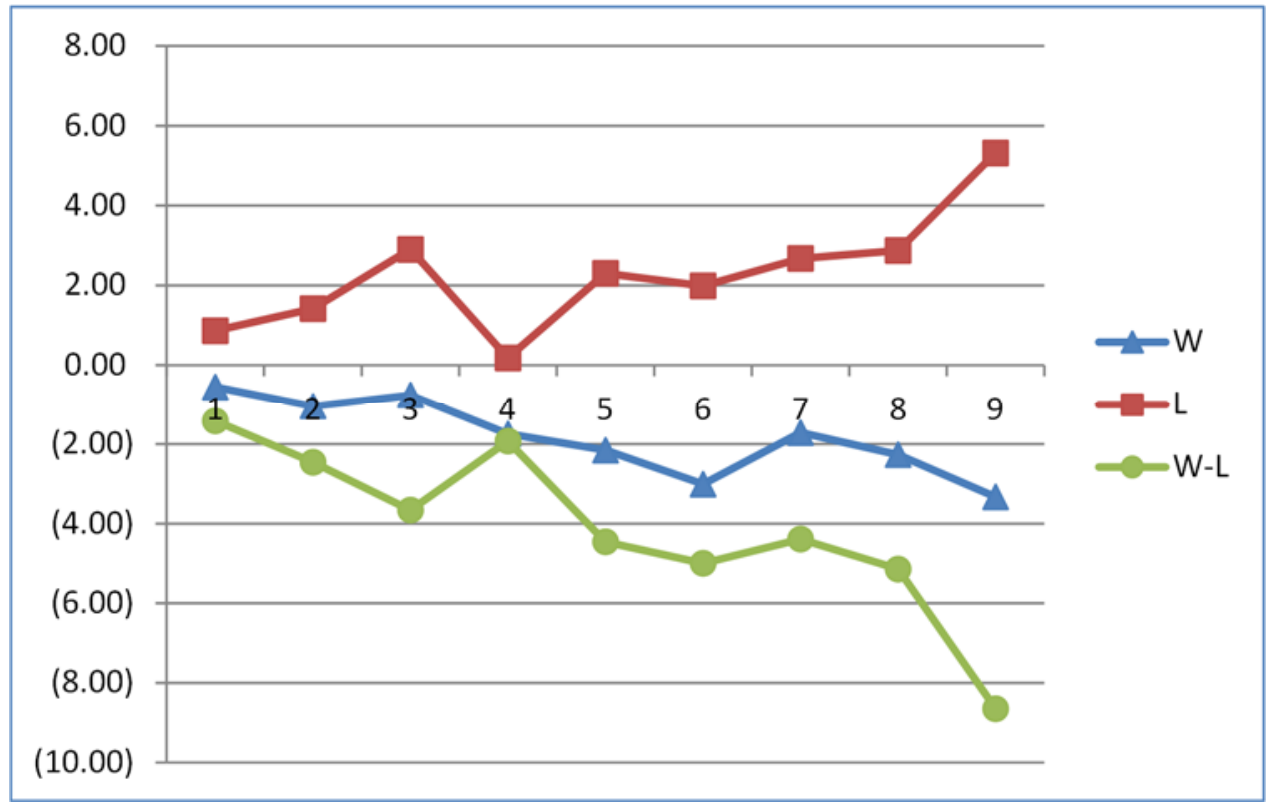

Figure 1. the broken line graph of the average values of AHCAR of momentum strategies in the whole cycle

Note: Abscissa 1-3 means the average values of AHCAR whose forming period is 2 weeks and holding period is 2, 4, 6 weeks.

Abscissa 4-6 means the average values of AHCAR whose forming period is 4 weeks and holding period is 2, 4, 6 weeks.

Abscissa 7-9 means the average values of AHCAR whose forming period is 6 weeks and holding period is 2, 4, 6 weeks.

From Figure 1 and Table 5, it can be see that:

1) The average cumulative abnormal returns of "loser" portfolios in different-length holding periods are positive values, which reflects that there is the conspicuous contrarian effect in weak stocks of Shanghai stock market.

2) The average cumulative abnormal returns of "winner" portfolios in different-length holding periods are negative values, which reflects that there is the conspicuous contrarian effect in strong stocks of Shanghai stock market too.

3) The average cumulative abnormal returns of buying "winner" portfolios and selling "loser" portfolios in different holding periods are negative values, and it is significant in the level of $10 \%$ when the forming period is 6 weeks, which reflects that there is the conspicuous contrarian effect in Shanghai stock market.

4) As the forming periods and holding periods are longer, the contrarian effect of Shanghai 
stock market is more reliable and more significant.

\subsection{Analysis results of Sub-cycle}

\subsubsection{Analysis results of bull cycle}

This section divides the entire research period into bull cycle and bear cycle, and this part examines the feasibility of momentum strategies in the bull market. Sample data is from July 1, 2014 to June 12, 2015. The relevant results are shown in Table 6 and Figure 2.

Table 6. The average values of AHCAR of momentum strategies in bull cycle

\begin{tabular}{|c|c|c|c|c|}
\hline \multirow{2}{*}{ Forming Periods } & & \multicolumn{3}{|c|}{ Holding Periods } \\
\hline & & 2 & 4 & 6 \\
\hline \multirow{6}{*}{2} & \multirow{2}{*}{ W } & 1.32009 & -0.36818 & 0.05224 \\
\hline & & $(1.80000)^{*}$ & $(-1.00000)$ & $(1.00000)$ \\
\hline & \multirow{2}{*}{$\mathrm{L}$} & -0.43642 & -0.96919 & 0.15235 \\
\hline & & $(-0.60000)$ & $(-0.60000)$ & $(0.20000)$ \\
\hline & \multirow{2}{*}{ W-L } & 1.75651 & 0.60101 & -0.10011 \\
\hline & & $(1.80000)^{*}$ & $(-0.20000)$ & $(0.20000)$ \\
\hline \multirow{6}{*}{4} & \multirow{2}{*}{ W } & -1.59543 & -1.36865 & -2.02649 \\
\hline & & $(-0.83205)$ & $(-0.27735)$ & $(0.27735)$ \\
\hline & \multirow{2}{*}{$\mathrm{L}$} & -0.81804 & 2.60185 & 3.10745 \\
\hline & & $(-1.38675)$ & $(0.27735)$ & $(0.83205)$ \\
\hline & \multirow{2}{*}{ W-L } & -0.77739 & -3.97051 & -5.13394 \\
\hline & & $(-0.27735)$ & $(0.27735)$ & $(0.27735)$ \\
\hline \multirow{6}{*}{6} & \multirow{2}{*}{ W } & 0.16953 & 0.52273 & -2.78586 \\
\hline & & $(0.33333)$ & $(0.33333)$ & $(0.33333)$ \\
\hline & \multirow{2}{*}{$\mathrm{L}$} & 4.60643 & 5.45641 & 7.12536 \\
\hline & & $(1.66667)^{*}$ & $(1.66667)^{*}$ & $(0.33333)$ \\
\hline & \multirow{2}{*}{ W-L } & -4.43690 & -4.93368 & -9.91121 \\
\hline & & $(1.00000)$ & $(1.00000)$ & $(1.66667)^{*}$ \\
\hline
\end{tabular}




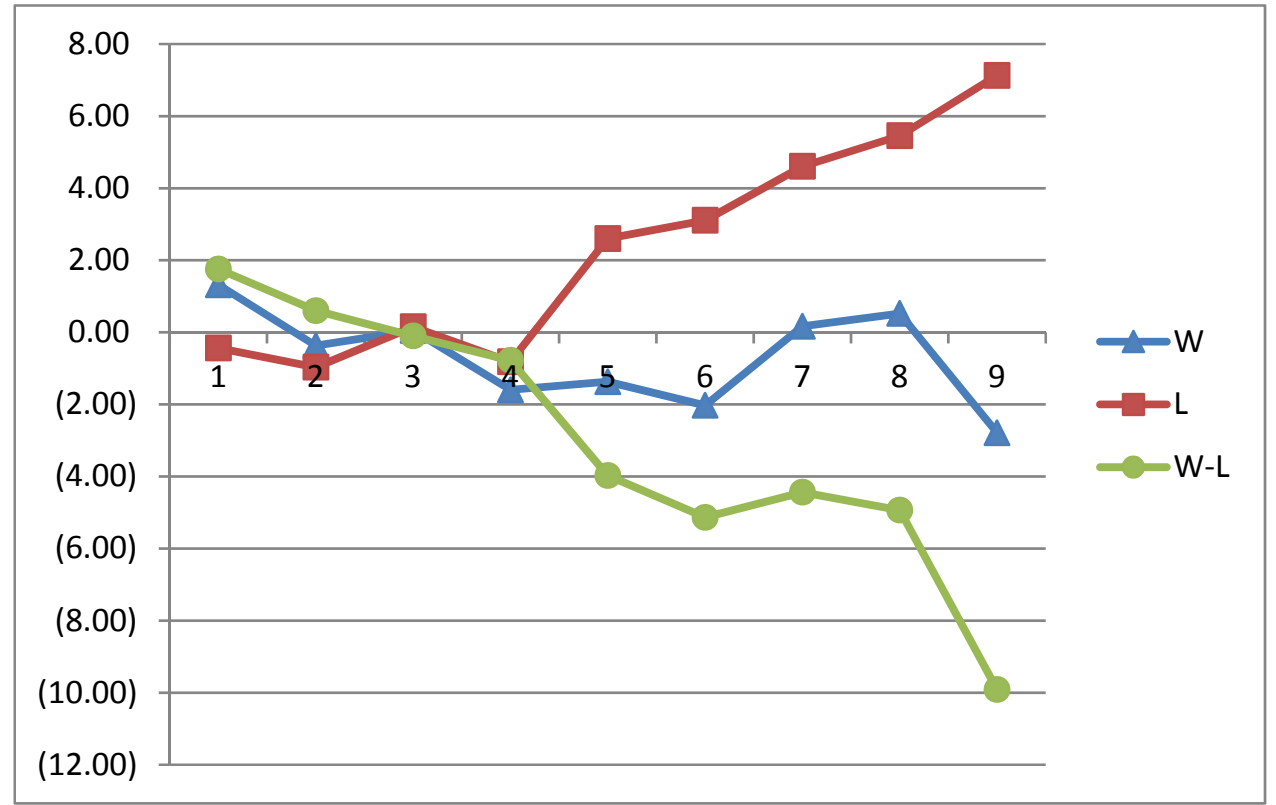

Figure 2. The broken line graph of the average values of AHCAR of momentum strategies in bull cycle

From Figure 2 and Table 6, it can be seen that:

1) In bull cycle, "loser" portfolios have momentum effect in Shanghai stock market when the forming period is 2 weeks.

2) In bull cycle, “loser” portfolios and W-L portfolios have contrarian effect in Shanghai stock market when the forming period is 4 or 6 weeks.

3) As the forming periods and holding periods are longer, the contrarian effect of Shanghai stock market is more reliable and more significant.

\subsubsection{Analysis results of bear cycle}

In bear cycle, the relevant results are shown in Table 7 and Figure 3. 
Table 7. The average values of AHCAR of momentum strategies in bear cycle

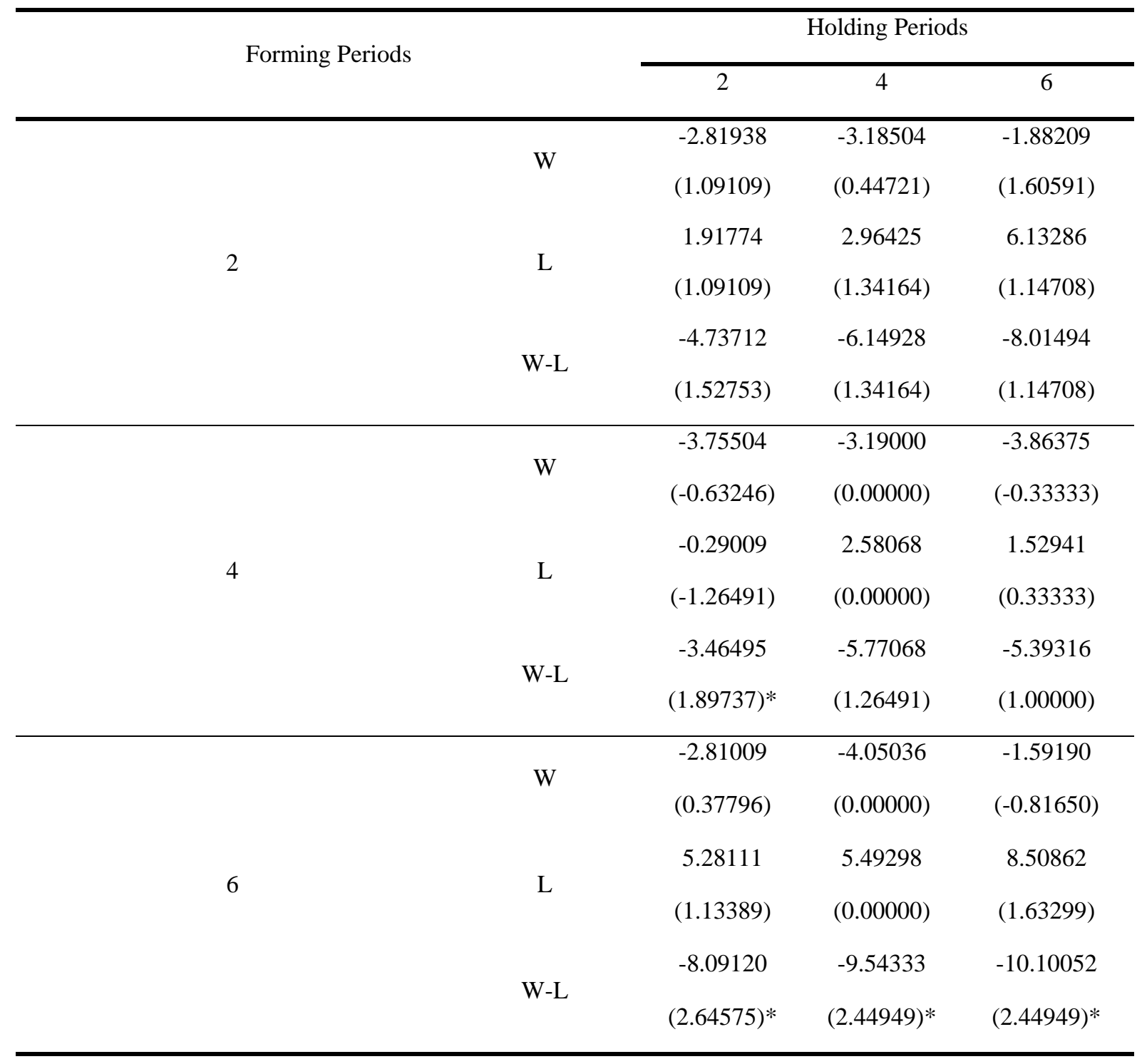




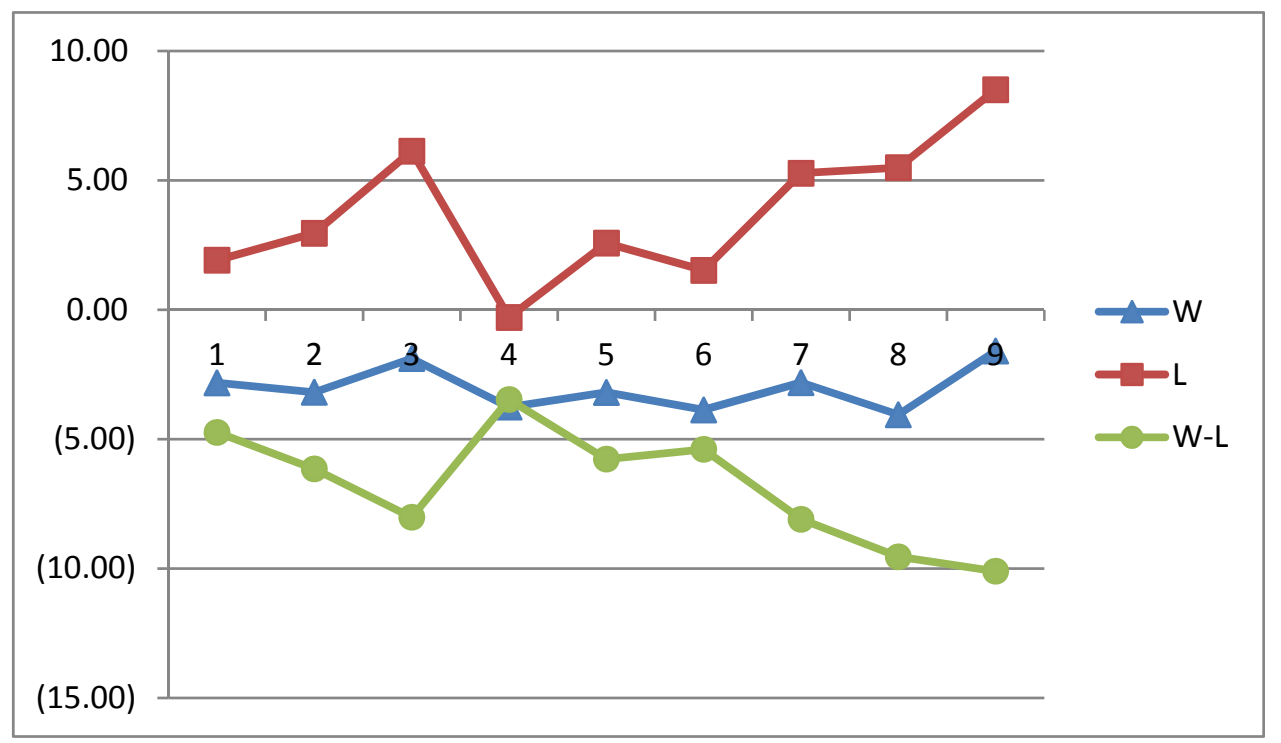

Figure 3. The broken line graph of the average values of AHCAR of momentum strategies in bear cycle

From Figure 3 and Table 7, it can be seen that:

1) In bear cycle, the average cumulative abnormal returns of "loser" portfolios in differentlength holding periods are positive values, which reflects that in bear cycle, there is the conspicuous contrarian effect in weak stocks of Shanghai stock market.

2) In bear period, the average cumulative abnormal returns of "winner" portfolios in different-length holding periods are negative values, which reflects that in bear period, there is the conspicuous contrarian effect in strong stocks of Shanghai stock market too.

3) In bear period, the average cumulative abnormal returns of buying "winner" portfolios and selling "loser" portfolios in different holding periods are negative values, and it is significant in the level of $10 \%$ when the forming period is 6 weeks, which reflects that in bear period, there is the conspicuous contrarian effect in Shanghai stock market.

\section{Conclusion}

Through analysis on the sample data of the full cycle, bull cycle and bear cycle, the paper concludes that: 
1. The analysis on the sample data of the full cycle indicates that there is conspicuous contrarian effect in Shanghai stock market. As the forming periods and holding periods are longer, the contrarian effect of Shanghai stock market is more reliable and more significant.

2. In bull cycle, there is conspicuous momentum effect in Shanghai stock market when the forming period is 2 weeks; there is conspicuous contrarian effect in Shanghai stock market when the forming period is 4 or 6 weeks.

3. In bear cycle, in different-length holding periods, there is conspicuous contrarian effect on Shanghai stock market, no matter weak stocks or strong stocks.

\section{References}

Bin Yang, Xiao Liu, Wenjing Shi. (2015) "Empirical Research on the Effect of Momentum Strategies of Chinese A share”, The Theory and Practice of Finance and Economics, vol. 31, no. 1, pp. 137-147.

Bo Liu, Tianlei Pi. (2007) "Momentum Strategies and Contrarian Strategies-New Evidence from Shanghai and Shenzhen A Share Markets in China”, Journal of Financial Research, no. 8, pp. 154-166.

DeBondt, Thaler. (1987) "Further Evidence on Investor Overreaction and Stock Market Seasonality”, Journal of Finance, no. 42, pp. 557-581.

Deyong Yang, Jiaqing Wang. (2013) "Empirical Research on Momentum Effect and Contrarian Effect in China A Share Market”, Journal of Jiangxi University of Finance \& Economics, no. 5, pp. 54-62.

Jegadeesh N., S.Titman. (1993) "Returns to Buying Winners and Selling Loses: Implications for Stock Market Efficiency”, Journal of Finance, no. 48, pp. 65-91. 
Ke Chen, Wei Chen. (2017) "Empirical Research on the Characteristics of A Share in Bull Market and Bear Market and the Trading Strategies to Sell into Corrections”, Special Zone Economy, no.2, pp. 46- 52.

Linjie Zhou. (2002) "Research on the Profitability of Momentum Strategies in China Stock Market”, The Journal of World Economy, no.8, pp. 60-64.

Taihua Yan, Lan Liang. (2009) "Research on the Momentum Effect of Shanghai Stock Market-Based on the Weekly Return Data from 1995 to 2009”, Technology Economics, vol. 30, no. 5, pp. 109-114.

Weihua Huang. (2015) "Empirical Analysis on the Momentum Strategies and China Stock Market”, The Theory and Practice of Finance and Economics, no. 2, pp. 46-52.

Werner F.M. DeBondt, Richard H. Thaler. (1985) “Does the Stock Market Overreact”, Journal of Finance, no. 40, pp. 793-805.

Xiaolei Liu. (2011) "Empirical Analysis on the Applicability of Momentum Strategies in China Stock Market”, Securities \& Futures of China, no.7, pp. 47-48.

Yi Wang. (2007) “Performance Research of Momentum Strategies”, The Journal Statistics and Consulting, no. 1, pp. 62-63.

Yonghong Wang and Xuejun Zhao. (2001) "Empirical Analysis on Momentum Strategies and Contrarian Strategies of China Stock Market”, Economic Research Journal, no. 6, pp. 56-89.

Zhanyu Zhu, Chongfeng Wu and Chengwei Wang. (2003) "Research on the Profitability of the Price Momentum of China Stock Market in Different Holding periods”, The Journal of World Economy, no. 8, pp. 62-67. 